\title{
First case of fungal keratitis caused by Pestalotiopsis clavispora
}

This article was published in the following Dove Press journal:

Clinical Ophthalmology

26 November 2013

Number of times this article has been viewed

\section{Yu Monden'}

Shohaku Yamamoto'

Ryoji Yamakawa'

Atsuko Sunada ${ }^{2}$

Seishi Asari ${ }^{3}$

Koichi Makimura ${ }^{4}$

Yoshitsugu Inoue ${ }^{5}$

'Department of Ophthalmology, Kurume University School of

Medicine, Fukuoka, ${ }^{2}$ Laboratory for Clinical Investigation, ${ }^{3}$ Department of Infection Control and Prevention, Osaka University Hospital, Osaka,

${ }^{4}$ Teikyo University Institute of Medical Mycology, Tokyo, ${ }^{5}$ Division of Ophthalmology and Visual Sciences, Tottori University Faculty of Medicine, Tottori, Japan
Correspondence: Yu Monden Department of Ophthalmology, Kurume University School of Medicine, 67 Asahi-machi, Kurume, Fukuoka 830-00II, Japan

$\mathrm{Tel}+81942317574$

Fax +81942370324

Email you@med.kurume-u.ac.jp
Purpose: To report the isolation of Pestalotiopsis clavispora from the cornea of a patient with recurrent keratitis.

Case report: A 73-year-old male gardener presented with conjunctival injection and an oval infiltrate with feathery margins in the temporal half of the cornea in the right eye. His ocular history in the right eye included cataract surgery, five episodes of herpes simplex keratitis, three glaucoma surgeries, and bullous keratopathy. He had been treated with corticosteroids for years. Light microscopy of corneal scrapings revealed a filamentous fungus, and fungal keratitis was diagnosed. Treatment with topical voriconazole and pimaricin ointment was commenced. One month later, the infiltrate resolved. The antifungal agents were discontinued 7 months later, and keratitis relapsed 4 days after the discontinuation. The fungus was isolated and identified by molecular techniques as $P$. clavispora. Based on the results of antifungal susceptibility testing, treatment with topical and intravenous micafungin was initiated. The corneal infiltrate resolved 1 month after the relapse.

Conclusion: Molecular identification of the pathogen, and antifungal susceptibility testing, are useful in treating patients with fungal keratitis caused by a rare human pathogen.

Keywords: fungal keratitis, Pestalotiopsis clavispora, plant pathogen, molecular identification, antifungal susceptibility test

\section{Introduction}

Pestalotiopsis spp., filamentous fungi, are well-known plant pathogens, and have been commonly isolated in subtropical and tropical regions. ${ }^{1}$ The genus Pestalotiopsis was established in 1949 by Steyaert, following a taxonomic amendment to the genus Pestalotia. Pestalotiopsis clavispora has been reported to cause a number of plant diseases, including diseases of blueberry and avocado plants. ${ }^{2,3}$ To our knowledge, this is the first case of human infection caused by $P$. clavispora.

\section{Case report}

A 73-year-old male gardener presented to Kurume University Hospital in Japan in April 2012 complaining of a foreign body sensation in his right eye after sweeping up leaves and twigs on a windy day. He had a medical history of hypertension, paroxysmal atrial fibrillation, and angina. He had previously received anticoagulation therapy with warfarin. His ocular history in the right eye included cataract surgery (1990), five episodes of herpes simplex keratitis (2006, 2007, 2008 [two times], and 2010), three glaucoma surgeries (2007 [two times] and 2008), and bullous keratopathy (2011). He had been treated with corticosteroids for years (Figure 1). 


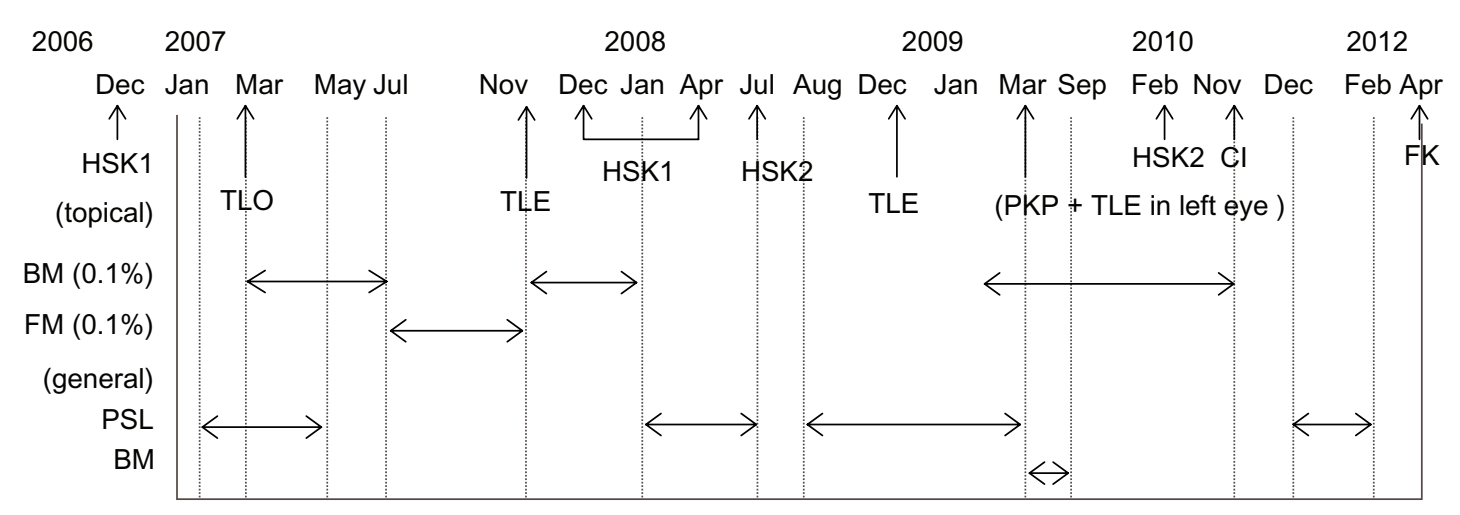

Figure I Previous treatment with corticosteroids.

Abbreviations: BM, betamethasone; FM, fluorometholone; PSL, prednisolone; HSKI, herpes simplex keratitis (geographic ulcer and stromal keratitis); TLO, trabeculotomy; TLE, trabeculectomy; HSK2, herpes simplex keratitis (stromal keratitis); PKP, penetrating keratoplasty; $\mathrm{Cl}$, corneal infiltration of unknown cause; FK, fungal keratitis.

At initial presentation, his visual acuity was hand motion in the right eye and 20/250 in the left eye. Intraocular pressure (IOP) was not measured in the right eye, and was $6 \mathrm{mmHg}$ in the left eye. Slit-lamp examination of the right eye revealed conjunctival injection and an oval infiltrate with feathery margins in the temporal half of the cornea (Figure 2A). Corneal opacity constrained visualization of the fundus in the right eye. Light microscopy of corneal scrapings taken from the right eye at initial presentation revealed uniformly thick septate hyphae (Figure 2B). The patient was diagnosed as having keratitis caused by a filamentous fungus, and was admitted to the hospital. A foreign body was found in the infiltrate when corneal debridement was performed (Figure $2 \mathrm{C}$ ). The foreign body could not be identified.

Topical corticosteroid treatment was discontinued, and topical treatment with voriconazole $1 \%$ hourly and pimaricin (natamycin) 1\% ointment six times per day was initiated. One week after admission, the infiltrate decreased in size by about $1 \mathrm{~mm}$. The patient was discharged at $1 \mathrm{month}$, after the infiltrate had resolved. At the time of discharge, visual acuity in his right eye was hand motion and IOP was $10 \mathrm{mmHg}$. Treatment with topical voriconazole four times per day, and pimaricin two times per day, was continued.

A search for the causative organism was initiated at the Central Clinical Laboratory of Kurume University Hospital, but the organism was not identified. The isolate was then sent to the Laboratory for Clinical Investigation at Osaka University Hospital, where it was examined morphologically. The isolate was suspected to be Pestalotiopsis spp., based upon light microscopy with lactophenol cotton blue staining, which revealed conidia-bearing appendages (Figure 2D).

A freshly isolated strain of Pestalotiopsis spp. from the clinical specimen was subcultured on potato dextrose agar (PDA) at $25^{\circ} \mathrm{C}$ for 7 days. An inoculum suspension was prepared in Roswell Park Memorial Institute (RPMI) 1640 medium and adjusted to a final inoculum of 10,000 conidia. The minimum inhibitory concentrations (MICs) for micafungin, amphotericin B, flucytosine, fluconazole, itraconazole, voriconazole, miconazole, and
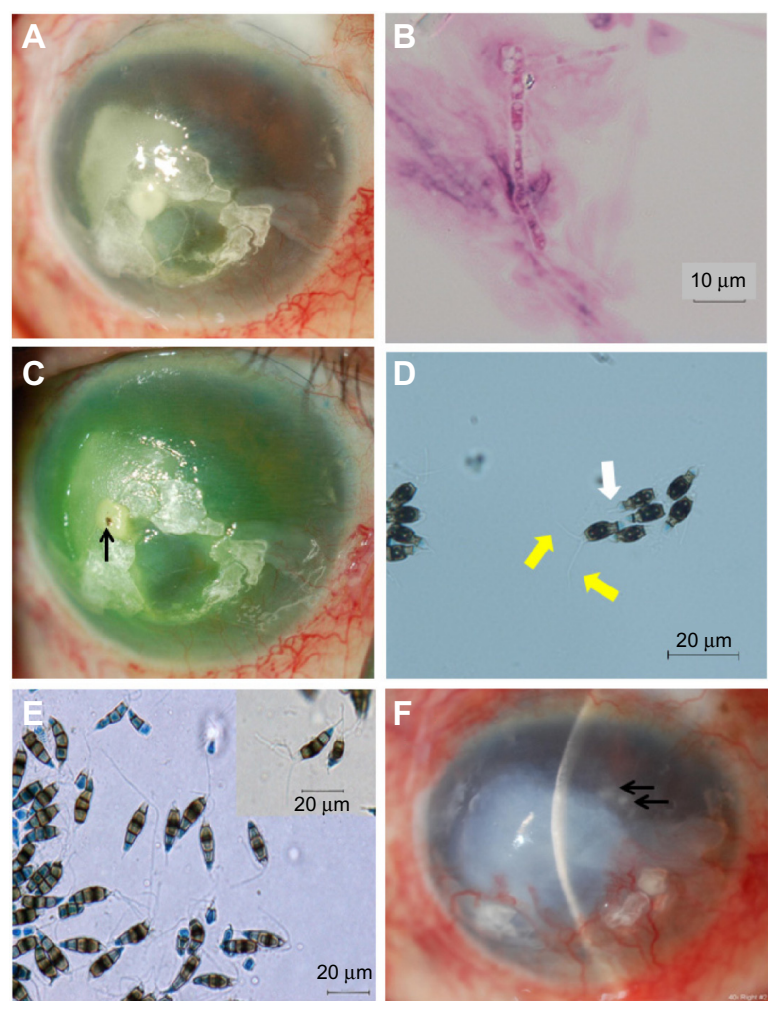

Figure 2 Slit-lamp and light microscopy photographs.

Notes: (A) Oval infiltrate with irregular margins in the temporal half of the cornea at initial presentation. (B) Light microscopy of corneal scrapings taken from the right eye at initial presentation revealed uniformly thick septate hyphae. (C) There was a foreign body in the central infiltrate after corneal debridement (arrow). (D) Light microscopy that revealed conidia with three apical appendages (yellow arrows) and a single basal appendage (white arrow) (lactophenol cotton blue staining; $\times 400$ ). (E) Microscopic findings of conidia produced on potato dextrose agar I month after incubation (lactophenol cotton blue staining; $\times 400$ ). (F) Relapse of the fungal keratitis, 8 months after discharge (arrows). 
pimaricin were determined by the method of microdilution in RPMI 1640 broth, according to the protocol approved by the Clinical and Laboratory Standards Institute. ${ }^{4}$ The final concentrations of the drugs were $0.015-16 \mu \mathrm{g} / \mathrm{mL}$ for micafungin, $0.03-16 \mu \mathrm{g} / \mathrm{mL}$ for amphotericin $\mathrm{B}$, miconazole, and pimaricin, $0.12-64 \mu \mathrm{g} / \mathrm{mL}$ for flucytosine and fluconazole, and $0.12-8 \mu \mathrm{g} / \mathrm{mL}$ for itraconazole and voriconazole. Frozen microplates were obtained from Eiken Chemical Co., Ltd. (Tokyo, Japan). For the assay, $100 \mu \mathrm{L}$ of adjusted inoculum were added, and the plates were incubated at $25^{\circ} \mathrm{C}$, without shaking. All MICs were read at 48 hours.

The isolate was sent to Teikyo University Institute of Medical Mycology for further morphological and molecular identification. A colony incubated on PDA at $27^{\circ} \mathrm{C}$ in the dark for one month revealed that the conidia were narrowly fusoid to fusoid-clavate, straight or somewhat curved, fivecelled, with the upper cell conical to cylindrical, hyaline, fairly thin-walled, without visible cellular contents, and bearing two to four rather stout central apical appendages, $10-20 \mu \mathrm{m}$ long and up to $1 \mu \mathrm{m}$ wide (Figure 2E). Based on these morphological characteristics, the isolate was identified as Pestalotiopsis spp. ${ }^{5}$

Fungal DNA was extracted from the isolate according to the rapid method described by Makimura et $a l,{ }^{6}$ and the internal transcribed spacer (ITS) region of the rRNA gene was sequenced directly from the polymerase chain reaction products with the ITS1-ITS4 universal primer pair. ${ }^{7}$

A Basic Local Alignment Search Tool (BLAST) search revealed the sequences had $100 \%$ similarity only to P. clavispora (EF119336), registered in the DDBJ/EMBL/ GenBank database, and less than $100 \%$ similarity to other species of Pestalotiopsis.

Although the isolate demonstrated relatively high resistance to voriconazole (MIC: $2.0 \mu \mathrm{g} / \mathrm{mL}$ ) and pimaricin (MIC: $2.0 \mu \mathrm{g} / \mathrm{mL}$ ) through antifungal susceptibility testing (Table 1), topical voriconazole and pimaricin continued to be used because the infiltrate decreased in size. Treatment was

Table I Antifungal susceptibility testing

\begin{tabular}{ll}
\hline Antifungal agent & MIC $(\mu \mathrm{g} / \mathrm{mL})$ \\
\hline Micafungin & 0.03 \\
Amphotericin B & 0.25 \\
Itraconazole & 2.0 \\
Miconazole & 2.0 \\
Pimaricin & 2.0 \\
Voriconazole & 2.0 \\
Flucytosine & 32 \\
Fluconazole & $>64$ \\
\hline
\end{tabular}

Abbreviation: MIC, minimum inhibitory concentration. discontinued 7 months after discharge, based upon the absence of conjunctival injection and corneal infiltrate. Four days later, the keratitis had relapsed (Figure 2F). Although fungus was not isolated from corneal scrapings at this time, treatment with topical micafungin (MIC: $0.03 \mu \mathrm{g} / \mathrm{mL}$ ) $0.1 \%$ half-hourly, intravenous micafungin $50 \mathrm{mg}$ daily, and corneal debridement weekly was commenced, based on the results of antifungal susceptibility testing. Liver function and prothrombin time/international normalized ratio (PT-INR) were monitored periodically during systemic micafungin administration. The corneal infiltrate resolved 1 month after the relapse. Intravenous micafungin was discontinued, and topical micafungin was tapered over 7 months, after resolution from half-hourly to three times per day. During this period, the conjunctival injection and the corneal infiltrate were not seen. Visual acuity in his right eye was hand motion at the final visit, 7 months after resolution. No side effects related to topical voriconazole and micafungin were noted during the 15-month follow-up. Topical micafungin will be discontinued 1 year after resolution.

\section{Discussion}

P. clavispora is a ubiquitous fungus found in soil and plants. A search for related studies was performed using the electronic database PubMed, until July 31 2013, using the search term "Pestalotiopsis clavispora". No human or animal infections caused by this organism have been reported to this date.

The patient was a gardener who presented with an eye infection after sweeping up leaves and twigs on a windy day. A foreign body was detected in the infiltrate when corneal debridement was performed. The right eye of this patient was predisposed to fungal infection, due to long-term use of corticosteroids, recurrent corneal surface disorders, and glaucoma (Figure 1). Rare human pathogens can cause keratitis in patients with a history of trauma or immunosuppression. ${ }^{8,9}$

Antifungal susceptibility testing of our organism showed low susceptibility to voriconazole and pimaricin, but high susceptibility to micafungin (Table 1). However, our initial treatment with topical voriconazole and pimaricin seemed to be effective in decreasing the infiltrate, because of the high concentrations that resulted from frequent administration of the antifungal agents. Keratitis relapsed after the antifungal agents were tapered and discontinued. The keratitis might have been smoldering, because of lower doses of voriconazole and pimaricin. Lowering the doses of voriconazole and pimaricin appears to have triggered the relapse, suggesting the treatment approach was inadequate, and that the initial 
medication should have been changed based on the results of the susceptibility testing.

Mochizuki et al reported that the corneal concentration of micafungin was $1.60-5.99 \mu \mathrm{g} / \mathrm{g}$, the aqueous concentration was $0.02-0.35 \mu \mathrm{g} / \mathrm{mL}$, and the vitreous concentration was $0.03-0.15 \mu \mathrm{g} / \mathrm{mL}$, when the dose of micafungin was 150-300 mg/day. ${ }^{10}$ The MIC for micafungin against the isolate from our patient was $0.03 \mu \mathrm{g} / \mathrm{mL}$. After the keratitis relapsed, our patient received treatment with topical micafungin $0.1 \%$ half-hourly, intravenous micafungin $50 \mathrm{mg}$ daily, and corneal debridement weekly. Although the dose of intravenous micafungin was much lower than the dose reported by Mochizuki et al, we consider micafungin to have penetrated the cornea and the aqueous humor because of the combined use of micafungin. In addition, corneal debridement might have promoted the penetration of micafungin.

In our case, it required about 4 months to identify the pathogen as $P$. clavispora. We suspected the pathogen to be Pestalotiopsis spp., based upon light microscopy with lactophenol cotton blue staining that revealed conidia bearing appendages, but the species was not yet identified (Figure 2D and E). Using molecular biology techniques, the causative organism was identified as $P$. clavispora. As in our case, it is often challenging to identify an organism in human keratitis caused by rare fungal pathogens. DNA sequencing was useful in identifying the pathogen in our case. In a strict sense, epitypification with living strains is necessary before clear results can be obtained. ${ }^{11}$ However, it is difficult to perform epitypification in clinical or biological laboratories. The isolated organism showed 100\% similarity using the Max Ident score of the BLAST search. We therefore strongly believe that the organism was $P$. clavispora.

This is the first report of $P$. clavispora from a patient with keratitis. The results suggest that even a plant pathogen can cause human infection in immunocompromised hosts. Antifungal susceptibility testing is beneficial for the treatment of fungal keratitis caused by rare fungal pathogens, and molecular biological techniques may be the only means to identify a rare fungus causing infection in humans.

\section{Disclosure}

The authors have no conflict of interest to disclose.

\section{References}

1. Yang XL, Zhang JZ, Luo DQ. The taxonomy, biology and chemistry of the fungal Pestalotiopsis genus. Nat Prod Rep. 2012;29(6):622-641.

2. Espinoza JG, Briceño EX, Keith LM, Latorre BA. Canker and twig dieback of blueberry caused by Pestalotiopsis spp. and a Truncatella sp. in Chile. Plant Dis. 2008;92(10):1407-1414.

3. Valencia AL, Torres R, Latorre BA. First report of Pestalotiopsis clavispora and Pestalotiopsis spp. Causing postharvest stem end rot of avocado in Chile. Plant Dis. 2011;95(4):492.

4. Clinical and Laboratory Standards Institute. Reference Method for Broth Dilution Antifungal Susceptibility Testing of Filamentous Fungi; Approved Standard. 2nd ed. CLSI document M38-A2. Wayne, PA: Clinical and Laboratory Standards Institute; 2008.

5. Crous PW, Verkley GJM, Groenewald JZ. Eucalyptus microfungi known from culture. 1. Cladoriella and Fulvoflamma genera nova, with notes on some other poorly known taxa. Stud Mycol. 2006;55(1):53-63.

6. Makimura K, Tamura Y, Mochizuki T, et al. Phylogenetic classification and species identification of dermatophyte strains based on DNA sequences of nuclear ribosomal internal transcribed spacer 1 regions. J Clin Microbiol. 1999;37(4):920-924.

7. Innis MA, Gelfand DH, Sninsky JJ, White TJ, editors. PCR protocols: A guide to methods and applications. San Diego, CA: Academic Press; 1990.

8. Malecha MA, Tarigopula S, Malecha MJ. Successful treatment of Paecilomyces lilacinus keratitis in a patient with a history of herpes simplex virus keratitis. Cornea. 2006;25(10):1240-1242.

9. Chew HF, Jungkind DL, Mah DY, et al. Post-traumatic fungal keratitis caused by Carpoligna sp. Cornea. 2010;29(4):449-452.

10. Mochizuki K, Sawada A, Suemori S, et al. Intraocular penetration of intravenous micafungin in inflamed human eyes. Antimicrob Agents Chemother. 2013;57(8):4027-4030.

11. Maharachchikumbura SSN, Guo LD, Chukeatirote E, Bahkali AH, Hyde KD. Pestalotiopsis - morphology, phylogeny, biochemistry and diversity. Fungal Divers. 2011;50(1):167-187.
Clinical Ophthalmology

\section{Publish your work in this journal}

Clinical Ophthalmology is an international, peer-reviewed journal covering all subspecialties within ophthalmology. Key topics include: Optometry; Visual science; Pharmacology and drug therapy in eye diseases; Basic Sciences; Primary and Secondary eye care; Patient Safety and Quality of Care Improvements. This journal is indexed on Submit your manuscript here: http://www.dovepress.com/clinical-ophthalmology-journal

\section{Dovepress}

PubMed Central and CAS, and is the official journal of The Society of Clinical Ophthalmology (SCO). The manuscript management system is completely online and includes a very quick and fair peer-review system, which is all easy to use. Visit http://www.dovepress.com/ testimonials.php to read real quotes from published authors. 